\title{
Numerical analysis, slope design and in situ stress
}

\author{
J. Sjöberg Itasca Consultants $A B$, Sweden
}

\begin{abstract}
This paper presents a brief review of the history of numerical modelling applied to the design of rock slopes, with contributions to previous slope stability symposia used to illustrate the development. The related issue of the effect of in situ (or initial) rock stresses on slope stability is also discussed in the paper. The use of numerical modelling has evolved significantly from the first, precarious, steps in the late 1960s. Currently, modelling is a standard tool in almost all slope design work and highly sophisticated models allow simulation of many (if not all) aspects of slope behaviour. Three-dimensional modelling is common and the use of models that allow explicit crack propagation, is slowly emerging. There is, however, still room for improvements within this field. Many of the existing modelling approaches have not been fully validated, mainly due to the problem of obtaining complete geometrical description and properties for all units within a fractured rock mass. The advance in data collection and generation of input data has not kept pace with the improvements in modelling techniques, and rock mechanics problems remains to a large extent data limited. There is a need for more encompassing data collection and monitoring systems for future modelling improvements. An improved characterisation will require extensive collaborative efforts between engineers, geologists, and geophysicists. In the future, a move towards real-time modelling can also be envisioned. This concept has not yet been fully applied in rock mechanics, but there are examples of applications in other engineering and scientific disciplines, such as weather forecasting and physics modelling, and some ideas are presented.
\end{abstract}

\section{$1 \quad$ Introduction}

Numerical modelling has become the preferred tool for rock mechanics analysis in almost all fields of application today. This development has been augmented through the rapid increases in computer capacity during the last few decades. This paper provides a review of some aspects of numerical modelling as applied to rock slope design. The review uses contributions from selected previous symposia focused on slope stability, as checkpoints to show the advance and use of modelling in slope design. The review is not intended to be complete; it merely provides some samples of the history of development mixed with my personal reflections on the subject. A related issue is the (possible) effect of the initial (in situ) stress on the stability of a slope, and this is also discussed in the paper.

\section{$2 \quad$ Numerical analysis for rock slope applications}

\subsection{The first steps}

In the first Slope Stability symposium in 1970, Brawner (1971) stated:

"The advent of the computer and the finite element technique have made it possible to incorporate the third dimension in stability studies. However, these new techniques are not a cure-all. When used with discretion, in the hands of experienced engineers, they are a powerful tool. In the hands of the inexperienced, they may only provide a quicker way of getting the wrong answer".

In this symposium volume, a total of 14 papers were published, including an introduction, a panel discussion and a symposium summary. The 11 technical papers covered economics, geology, groundwater, blasting, earthquakes, stability analysis, instrumentation and monitoring, stabilisation methods, tailings dams, and case studies. Numerical modelling was briefly mentioned on a quarter of a page, including a 
figure of a coarse finite element mesh, in Chapter 8 (Pentz, 1971). It was mentioned that displacements in two dimensions may be computed and that joints and faults can be modelled using Goodman's approach with so-called 'joint elements' (Goodman and Taylor, 1966; Goodman et al., 1968) - although there is a limit to the number of such features that can be included. The necessity of having to include geological structures into the model was thus recognised early, but the technology was not yet readily available. In the panel discussion at the symposium, there was no discussion on the use of modelling for slope design.

The U.S. Rock Mechanics Symposium the following year (1971) was devoted to rock slope stability (Cording, 1972). In these proceedings, numerical modelling was dealt with in three papers (from a total of 23 papers on slope stability). One paper described the emerging technique of discrete element modelling (Ko, 1972). The use of joint elements had been extended to three-dimensional analysis (Mathab and Goodman, 1970) however discrete element modelling would also allow discrete slip along simulated discontinuities. Only a generic case was studied in the paper, but the tool as such had great promise.

An interesting case from the same symposium was that of the Berkeley pit (Pariseau and Stout, 1972) in which numerical modelling was used for a practical application. This may have been one of the first such cases published. The model used, see Figure 1, was simple by today's standards, but the Berkeley pit case study is still interesting in many ways. A generic parameter study was first conducted to assess sensitivity of parameters and partly based on this, stiffness and strength properties for use in the model were reduced by a factor of 10 from their laboratory values. Thus, a scale effect for the large scale rock mass strength was actually accounted for in the analyses. Moreover, a set of potential failure surfaces were evaluated for various mining depths, to assess stable overall slope angles. The paper is concluded with the statement that rock slope stability is: a subject where deductions abound but facts are few. The work presented in that paper is in fact a good early example of the opposite, where a pragmatic modelling approach, coupled with field studies and engineering judgement, provide facts that design decisions can be based on.

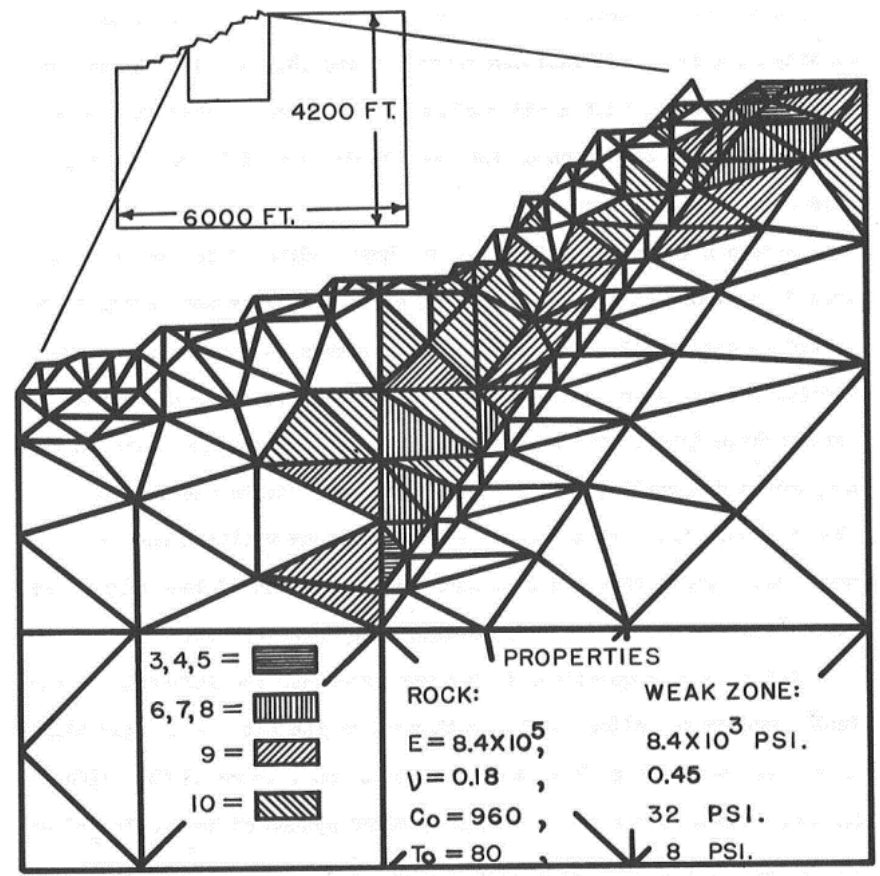

Figure 1 Two-dimensional finite-element model used to analyse the Berkeley pit (from Pariseau and Stout, 1972)

The above examples are representative of the state of numerical modelling at this time. The use of modelling was restricted to specific cases, often research projects with large budgets, and where highly qualified specialists conducted the actual modelling. At the same time, the numerical models employed were, with today's standards, very simple, being two-dimensional and limited in size and resolution 
(number and size of elements). Nevertheless, there was an air of optimism regarding the future use of numerical analysis in this field.

\subsection{Two-dimensional developments}

Let us fast-forward 30 years to the fourth symposium on slope stability, which was held almost 20 years after the third one, this time in Denver, Colorado, in 2001 (Hustrulid et al., 2001). During this 20 year hiatus in the symposium series, the art of numerical modelling had developed significantly. During the 1980s and even more so, the 1990s, modelling tools had become commercially available at relatively low cost and the tools were now used by consulting firms, mining companies, contractors, etc.

At the Denver symposium, numerical modelling was mentioned in 13 out of 28 papers dealing with pit slope stability issues. The majority of these were two-dimensional applications in which both continuum and discontinuum models were used. However, a few three-dimensional modelling applications were also presented. In this fourth symposium on slope stability, all papers were specially invited, which may have influenced the topics presented and the amount of numerical modelling cases presented. Nevertheless, it was clear that two-dimensional modelling had come of age and was routinely used in many cases and operations worldwide. At this time, modelling was typically used to improve understanding of slope behaviour through e.g. parametric studies, forensic investigations and sometimes back-analyses of observed failures. The investigation of complex toppling behaviour by Board et al. (1996) is one example of where modelling was used to confirm field observations and identify the governing failure mechanism.

Another example is that of the Aznalcóllar open pit, in which two-dimensional modelling was used to understand the behaviour of a pit slope during its final stages of mining. By modelling different scenarios in terms of lithology and rock mass parameters (both of which were subject to some uncertainty), it was possible to understand the somewhat contradictory observations made during mining. It became clear that a slice of pyrite left unmined at the toe of the slope inhibited failure to develop fully during mining, and that the ultimate failure surface was more deep-seated than indicated by for example, inclinometer readings. The modelling also showed that failure occurred as combined shear-tensile failure through the rock mass - not along large structures. An example of modelling output is shown in Figure 2, and the interpreted failure development is illustrated in Figure 3 . Since this study was conducted subsequent to the finalisation of mining, these findings did not provide any input to slope design and/or remedial measures. Several fortunate circumstances helped to avoid a rapid and uncontrollable failure, including the thickness of the pyrite left in the footwall, and the waste backfilling of the pit directly after mining completion. 


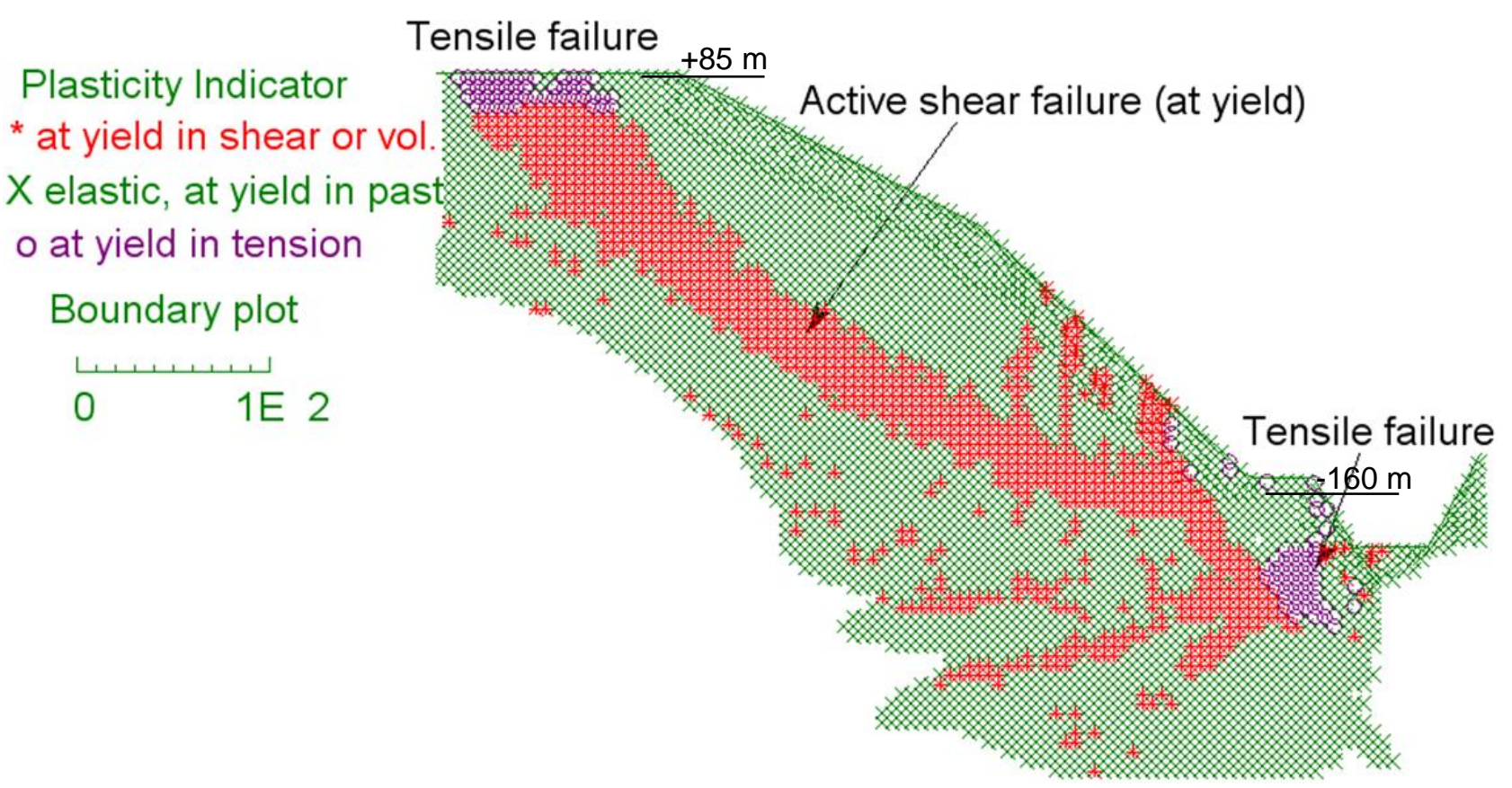

Figure 2 Yielding as inferred from numerical modelling of the eastern footwall at Aznalcóllar (from Sjöberg, 1999)
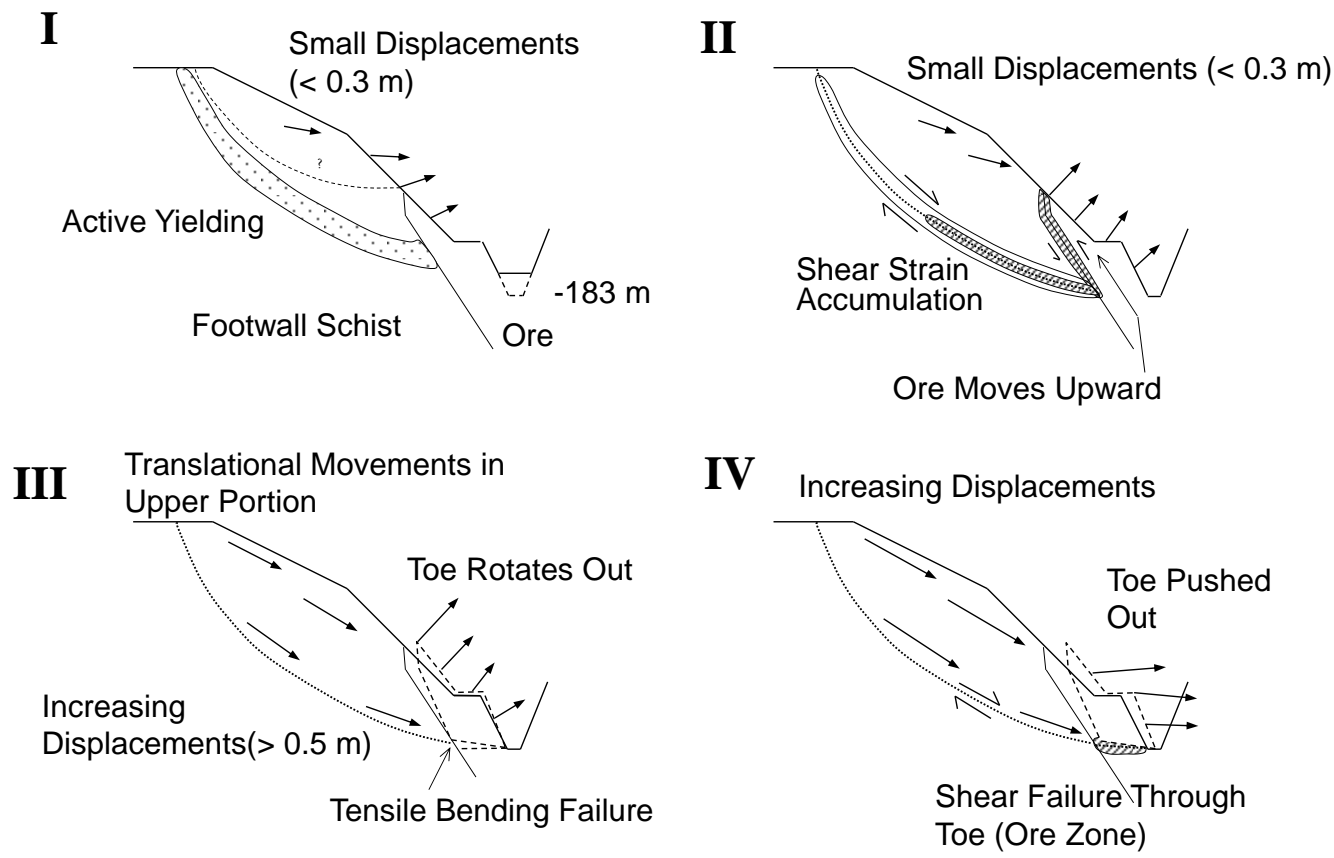

Figure 3 Failure development in the eastern footwall of the Aznalcóllar open pit (from Sjöberg, 1999)

Cases of forward analysis for use in slope design were also becoming more common. An example of this is the paper by Coulthard and Little (1999) on the Ok Tedi open pit. In this paper, current and future mining geometries were modelled using a range of parameter values, thus identifying the most important factors governing future slope stability. In this model, a strain-softening constitutive model was used with peak and residual strength according to undisturbed and disturbed conditions, respectively, in the Hoek-Brown failure criterion, which is a good example of the increased use of more sophisticated material models. However, it should be noted that the models were not validated by comparison against observed failures. 
Methods to calculate Factors of Safety through numerical modelling were also being developed at this time. The use of safety factors is often prompted by authority regulations and in guidelines, which frequently also stipulate the use of limit equilibrium methods. The shear strength reduction technique (see Dawson et al., 1999) was now employed to instead calculate safety factors using numerical modelling, thus providing a full solution of the coupled stress/displacement, equilibrium and constitutive equations.

Compared to limit equilibrium methods, the use of numerical modelling offers several advantages, e.g. (i) no need to specify trial failure surfaces in advance, (ii) no artificial parameters (such as functions for interslice force angles), (iii) multiple failure surfaces considered automatically, (iv) structural interaction may be included, and (iv) only kinematically feasible mechanisms considered (Dawson et al., 1999; Cala and Flisiak, 2001). However, simply using numerical modelling tools to calculate a Factor of Safety means that other benefits of modelling are ignored. Much more information can be extracted from a numerical model compared to limit equilibrium analyses. The cases discussed above are representative of the move towards improved understanding through modelling that characterised this time period. A comparison of the general status and approach in numerical modelling between the early 2000s and the early 1970s is presented in Table 1.

\subsection{Three-dimensions and fracture propagation}

The series on Slope Stability symposium was continued in Cape Town in 2006, followed by the one in Perth in 2007 (Potvin, 2007). At the 2007 symposium, there was one session in the proceedings devoted to numerical modelling of rock slopes. Numerical modelling was mentioned in nine papers out of a total of 40 for the whole symposium. Of these nine papers, only one paper dealt with three-dimensional modelling. It appeared, however, that some of the other cases described were three-dimensional and that the two-dimensional representations used may have oversimplified the problem.

At the latest Slope Stability symposium, held in Vancouver in 2011, there was one session on numerical analysis and slope design, comprising 12 papers (Eberhardt and Stead, 2011). Seven of these dealt with numerical modelling, and three-dimensional modelling was described in two of the papers. Wines and Hewson (2011) described a case in which the effects of relict voids from historic mining beneath the Kalgoorlie Super Pit were analysed. Modelling was conducted using a three-dimensional distinct element method, and the entire open pit was simulated together with more than 100 discrete, small scale void openings in the rock mass, see Figure 4 . This is an example of how the development in computer capacity now enabled larger, and at the same time, more detailed, numerical models to be analysed efficiently.

Table 1 Development in the use of numerical modelling (partly from Nordlund, 2010)

\begin{tabular}{|c|c|c|}
\hline Item & 25-30 Years Ago & Today \\
\hline Codes & $\begin{array}{l}\text { Homemade, could only be run } \\
\text { efficiently by its creator }\end{array}$ & $\begin{array}{l}\text { Many commercially available codes, } \\
\text { technical support and development }\end{array}$ \\
\hline Numerical methods & Only finite element (FEM) & $\begin{array}{l}\text { Many methods: FEM, FDM, BEM, } \\
\text { DEM, PFC, and hybrid methods }\end{array}$ \\
\hline Input and output & Craftsmanship, manual input & Interactive, large flexibility \\
\hline User requirement & $\begin{array}{l}\text { Steep learning curve } \\
\text { Long training time }\end{array}$ & $\begin{array}{l}\text { Shorter training time } \\
\text { (learning curve can still be steep) }\end{array}$ \\
\hline Material models & Linear-elastic & Elastic, plastic, visco-plastic, etc. \\
\hline Interpretation & $\begin{array}{c}\text { Numerous plots (stress, deformation, } \\
\text { etc.) but seldom combined } \\
\text { interpretation }\end{array}$ & $\begin{array}{l}\text { User-defined plots and criteria, large } \\
\text { flexibility }\end{array}$ \\
\hline $\begin{aligned} \mathrm{FEM} & =\text { Finite element method } \\
\mathrm{BEM} & =\text { Boundary element meth }\end{aligned}$ & difference met & \\
\hline
\end{tabular}




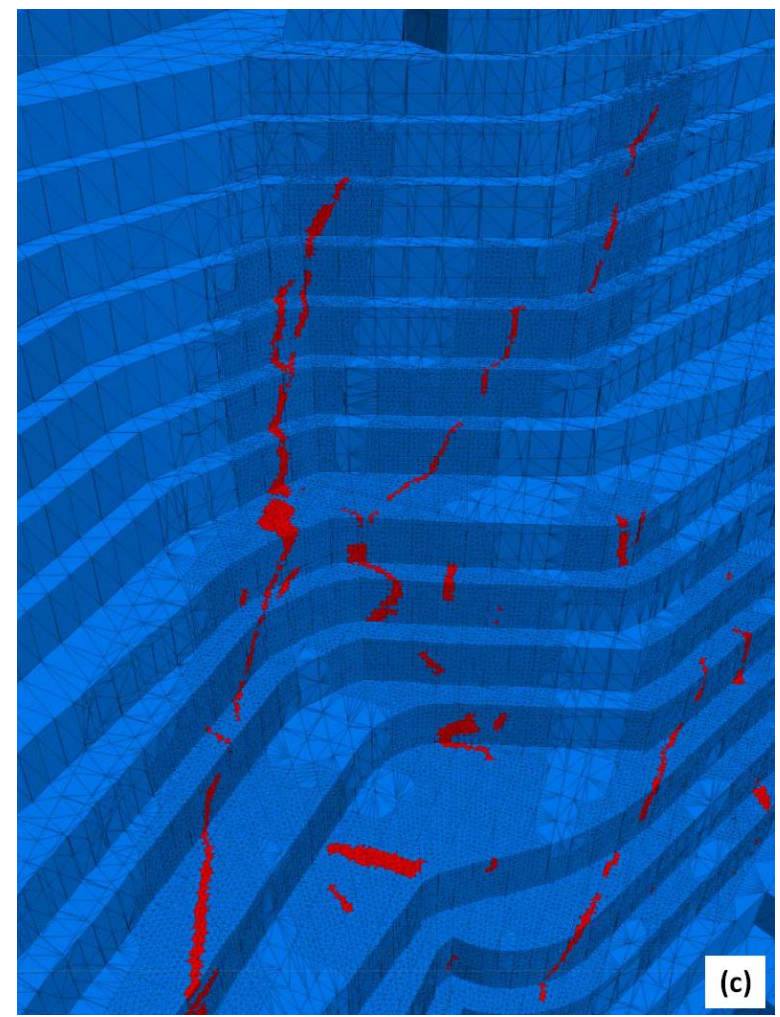

Figure 4 Oblique view of part of the final northwestern wall showing stope traces and surrounding 3DEC (Itasca, 2013) zones (from Wines and Hewson, 2011)

A few numerical modelling examples were presented in other sessions at the symposium, but three-dimensional applications were scarce. This is somewhat surprising considering that threedimensional tools were now readily available. The advances in pre-processing had also greatly facilitated model set-up for complex geometries, so one would assume that three-dimensional tools had been put to more use. It appears, however, that three-dimensional modelling was used quite extensively in consulting work as well as within larger mining corporations, but perhaps there is insufficient emphasis on publishing extensively (sometimes due to confidentiality aspects, sometimes due to lack of time).

At the 2007 symposium, there were also three papers on explicit modelling of fracture propagation using discontinuum and/or hybrid methods, and at the 2011 symposium, there were two such papers. The paper by Elmo et al. (2011) described explicit simulation of rock fracturing using the hybrid FEM/DEM numerical code ELFEN. Crack propagation in ELFEN is achieved through a transition from continuum to discontinuum (where cracks form) and associated re-meshing of the element generation (Munjiza, 2004; Klerck et al., 2004). The same approach was used by Stead et al. (2007). Input to the model was, in addition to rock material properties, a discrete fracture network (DFN) model, to represent rock mass fracturing. The models were not fully calibrated, but provided some insight into possible modes of failure for the studied pit slope. An example of analysis results in which a fully continuous failure surface could be traced - but for two different failure modes depending on the assumptions made - is shown in Figure 5. 

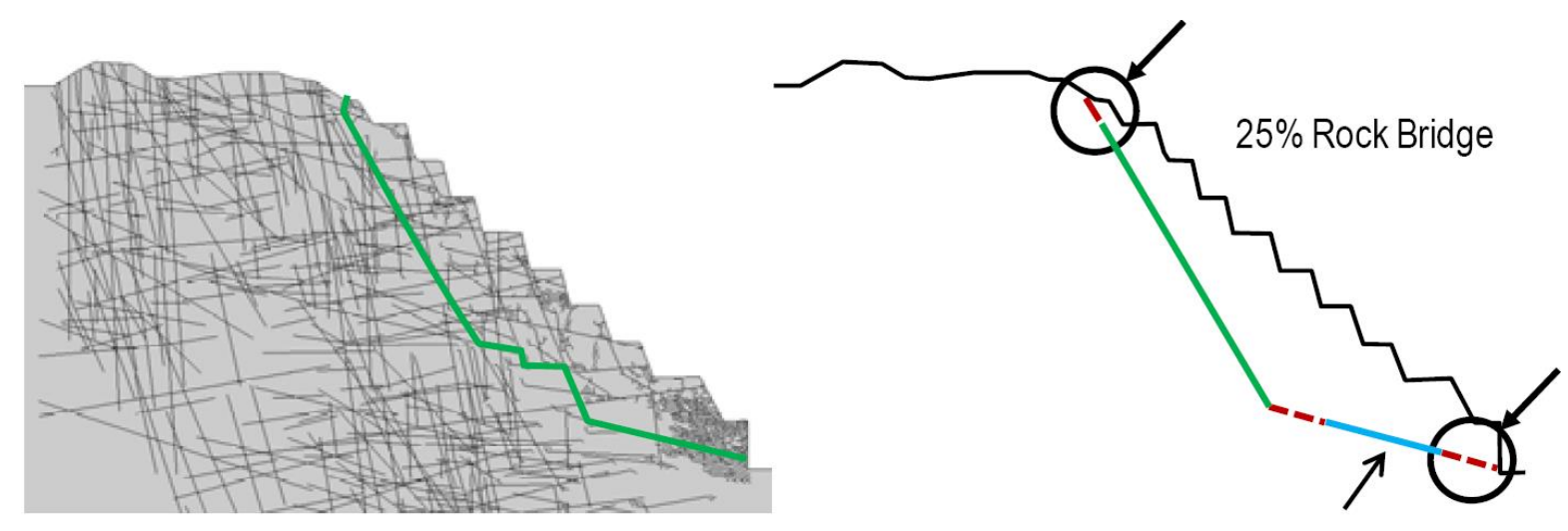

Input $15^{\circ}$ joint
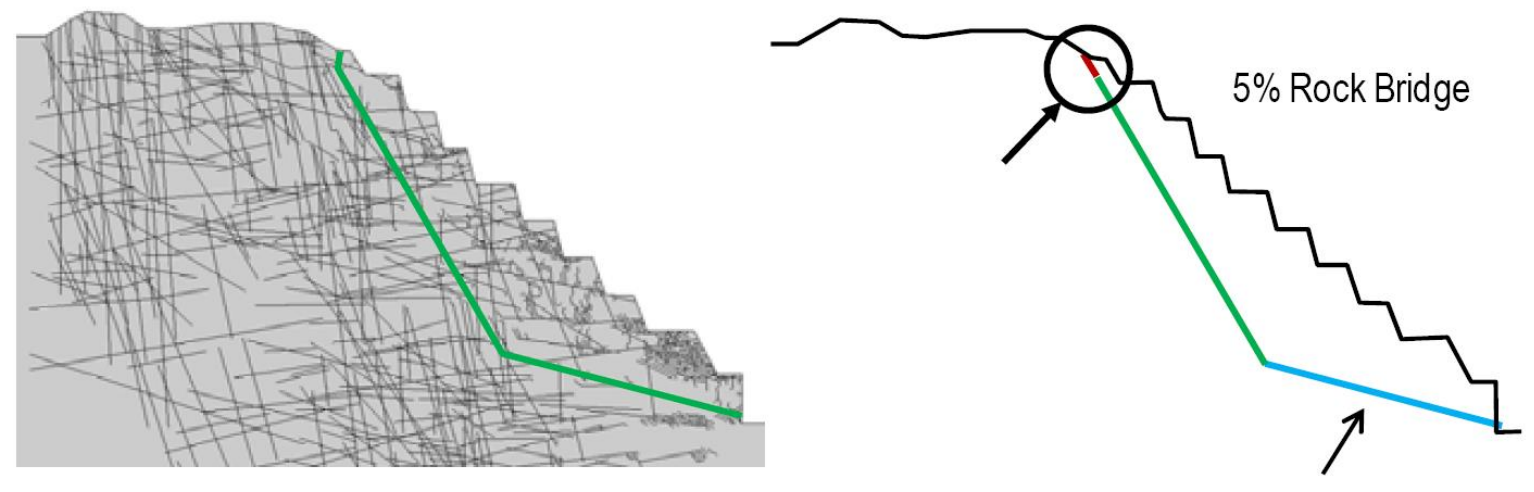

Input $15^{\circ}$ joint

Figure 5 Two-dimensional FEM/DEM results from Elmo et al. (2011), with black arrows/circles indicating the areas of failed rock

The developments in terms of explicit fracturing simulation are worth considering in more detail. An early approach was that by Napier and Hildyard (1992) in which both shear and tensile fracture growth could be modelled in two dimensions. The work by Shen (1993) also incorporated shear and tensile fracturing through an energy criterion. This work has later resulted in the commercially available code FRACOD ${ }^{2 D}$. ELFEN (mentioned above) has also been used in some mining cases. A slightly different approach to simulating the rock material is through a granular model using the discrete element method, starting with the work by Cundall and Strack (1979) and culminating in the commercially available codes PFC and PFC3D. Here, the particles (disk in 2D and spheres in 3D) may represent loose grains in a granular material like sand, or they may be bonded together to represent a solid material. Building upon this platform is the synthetic rock mass (SRM) approach, see also Figure 6. 


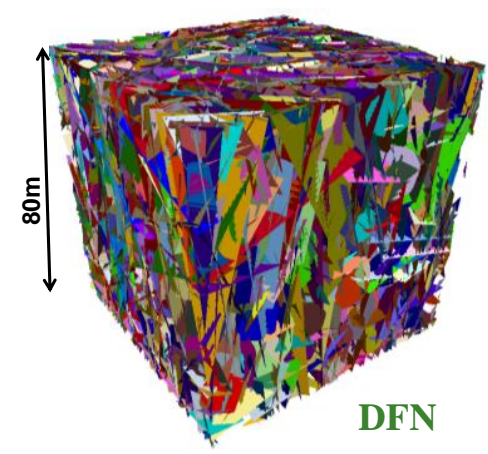

(a)

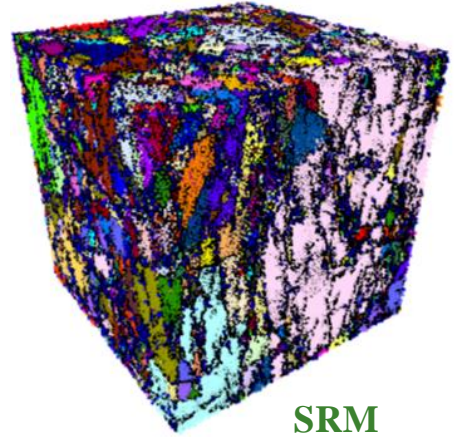

(b)

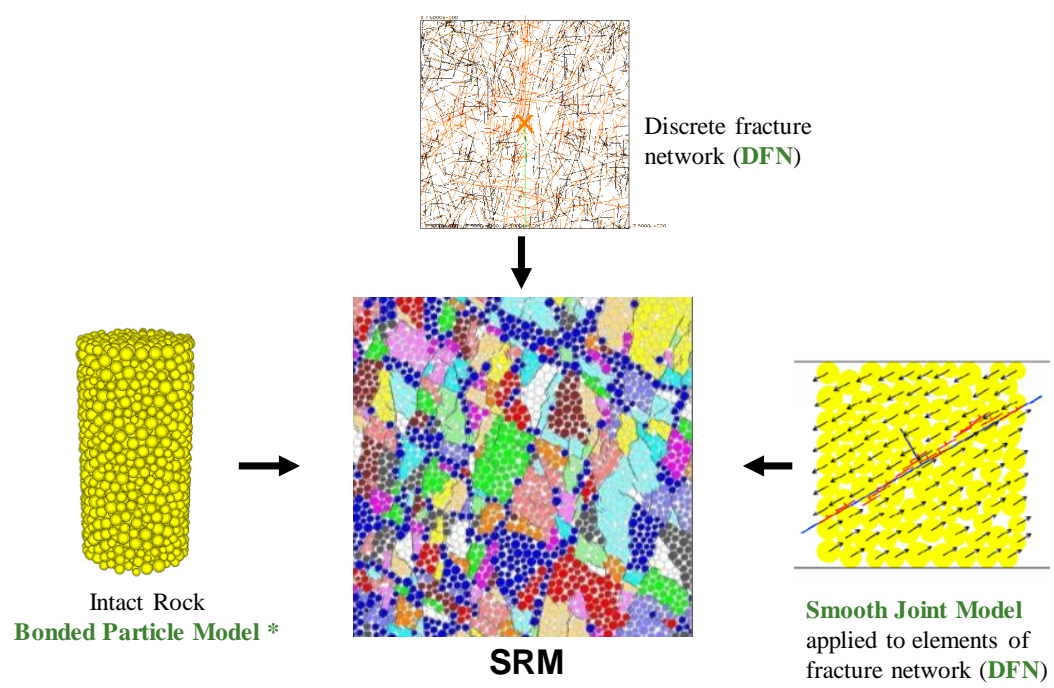

(c)

Figure 6 The SRM modelling approach; (a) three-dimensional discrete fracture network; (b) the corresponding three-dimensional synthetic rock mass sample; and (c) synthetic rock mass basic components (from Mas Ivars et al., 2011)

In this approach, a more explicit representation of the rock mass components is attempted; see Mas Ivars et al. (2011). The SRM method is based on the generation and testing of three-dimensional numerical (synthetic) rock mass samples. It uses a bonded particle model for rock for simulation of the brittle fracture of intact rock blocks (Potyondy and Cundall, 2004), and a discrete fracture network (DFN) modelling to represent jointing of the rock mass. Each individual joint is represented explicitly within the SRM sample, using the so-called 'smooth joint' contact model (Mas Ivars, 2010), see also Figure 6. Currently, it is possible to include thousands of non-persistent joints in an SRM sample. The SRM approach is currently developed for application to rock masses at the scale of 10-100 $\mathrm{m}$, and factors affecting the rock mass behaviour at the grain scale (grain size and shape, etc.) are not addressed explicitly.

The attractiveness of the SRM approach is that it, through PFC, allows for block breakage including considering the effect of incomplete joints on block strength and deformability. Furthermore, there is now a well-established methodology of how to obtain input data and generate SRM samples, as well as several examples of application of the results. However, it is not (yet) possible to do mine-scale models with the SRM concept. For mine-scale models, one is currently forced to use the SRM results as input to other continuum or discontinuum codes and model the rock mass as an equivalent material.

Following the Denver symposium in 2001, it had become clear that the large, deep pits emerging, with depths approach $1,000 \mathrm{~m}$, would put higher demands on the overall slope design procedure. Prompted by this, the Large Open Pit (LOP) project was started as a collaborative research effort with combined funding from many of the major mining companies worldwide. One visible result of this project, in addition to the 
competence and know-how built up within the participating organisations, was the book 'Guidelines for Open Pit Slope Design' (Read and Stacey, 2009), in which the state-of-the-art on slope design was presented.

Another outcome of the LOP project was the development of a new numerical technique to simulate large scale rock slopes including a very large number of pre-existing discontinuities, the so-called Slope Model (Lorig et al., 2009). This tool uses a lattice scheme, consisting of point masses (nodes) joined by springs, which simulates discontinuities and new fractures in the same manner as DEM but runs five to ten times faster. The lattice scheme is efficient because it pre-calculates geometrical and interaction data and uses simplified equations of motion. It is good for stiff, brittle rock in which (a) failure occurs at small strain, and (b) failure is by tensile rupture (e.g. fracture of rock bridges, hydrofracturing and blast damage), see Cundall (2011). Fluid flow in the joints and the rock matrix can also be simulated, including flow in fractures that form during the calculation. The lattice code is fully three-dimensional. A series of validation runs have been carried out, encompassing wedge failure, toppling failure, flow and effective stress formulation, etc., resulting in good comparison with physical results.

\section{$3 \quad$ Stresses and slope stability}

\subsection{Introduction}

The initial, or virgin, stress in the rock is defined as the stress prior to any excavation. Sometimes, this is also referred to as in situ stress. The stress state is obviously altered due to rock excavation, whether underground or in an open pit or a cut slope, and areas of both higher and lower stress (compared with the initial stress) will develop. In a rock slope, pit walls will in general become distressed close to the slope face, whereas stress concentrations will develop at the toe of the slope.

The effects of the initial stress state on the stability of rock slopes have been subject to some debate over the years. It has often been stated that the stresses in slopes are low and thus of less significance. Read and Keeney (2009) stated that:

"In open pit mining however, the stress environment is dilationary not confining and most slope failure are believed to be gravity-driven. Consequently, the effects of virgin in situ stresses are thought to be minimal and are not routinely measured for slopes".

The above statement is rather representative of the general view of stress effects. However, Read and Keeney (2009) goes on to say:

"In the current environment of increasingly deeper open pits, however, regional virgin stresses should perhaps be measured, particularly if it is thought that the stresses at the bottom of the pit are likely to be higher than the strength of the rock. The authors also note that it would be an advantage to know the initial stress as input to numerical analysis, to further analyse their relevance".

\subsection{A historical overview}

In the panel discussion following the first symposium on slope stability in Vancouver, 1970, the issue of tectonic horizontal stress (i.e. initial horizontal stresses being higher than the gravitational vertical stress) was briefly discussed (Brawner, 1971). No clear consensus on whether this would influence open pits was reached, but at the same it was stated that this was an area that could not be ignored in the future.

Pioneering work in this area includes the photoelastic analysis by Hoek and Pentz (1968), and numerical analysis by Stacey $(1970,1973)$. The studies by Stacey showed that de-stressing from horizontal stresses became more pronounced for steeper rock slopes. Varying the horizontal initial stress had a very large effect on both magnitudes and orientations of the resulting principal stresses after excavation. The paper by Dodd and Anderson (1972) concluded, through two-dimensional finite element modelling, that there is a need to include the effect of tectonic horizontal stresses into the studies of slope stability. The studies by 
Nilsen (1979) and Coulthard et al. (1992) showed that tensile stresses developed at the crest of the slope, with larger tensile zones for higher virgin horizontal stress and steeper slope angles. More recently, Noorani et al. (2011) investigated the effects of horizontal-to-vertical stress ratio in terms of failure initiation and propagation, using 2D numerical modelling. They found a fairly strong dependence on horizontal stress regarding where a large scale slope failure initiates.

Validations of the above statements are scarce. Stacey $(1970,1973)$ compared calculated stresses with measured stresses at the Kimbley pit (Blake, 1968) and found relatively good agreement between the two. Nilsen (1979) and Broch and Nilsen (1982) compared calculated stresses around an open pit in Norway with measured stresses in a drift close to the pit. A qualitative agreement was found, indicating the same orientation and the same order of magnitude of the principal stresses.

Some of the three-dimensional stress effects in pit slopes were also quantified by Stacey (1973), using a three-dimensional numerical model. The effects of slope curvature were addressed by Hoek and Bray (1981). Based on experience and observations, an increase in stable slope angle (up to $10^{\circ}$ ) could be anticipated with a decrease of curvature, i.e. more confined conditions. Lorig (1999) confirmed, through axisymmetric numerical modelling, that when the radius of curvature of a concave slope is less than the height of the slope, the slope angle can be $10^{\circ}$ higher than for a two-dimensional (no curvature considered) case. This stress effect was also modelled numerically by Zettler et al. (1999), confirming the increase in stability for concave slopes compared to convex ones.

Similar studies and comments can be found elsewhere in the existing literature during the last 40 years concerning stress effects for rock slopes. The lack of consensus implies that either the influence of initial stress state on rock slope stability has not proven to be very important, or that the whole issue has largely been ignored and is still poorly understood. In many cases, the uncertainty of other parameters such as geology, rock mass strength, and groundwater conditions, has a larger influence on slope behaviour than stress variations, as discussed by Hoek et al. (2009). However, they go on to say that more careful consideration is required for cases with high horizontal stresses, where underground excavations are located close to a pit, and for very large deep pits. Stacey (2007) and Dight (2006) presented several examples of unexpected slope failures, in which stresses likely played an important role, even for pits and slopes of fairly moderate size. Both the stress state and the resulting mechanisms of failure are subject to uncertainty in these cases.

It appears that validation studies are lacking, which, in turn, means that more measurements of the actual stress state may be justifiable. There are a few examples of application of stress measurements in slopes in the literature, see Obara et al. (2000). However, essentially the same measurement methods as used for underground applications can be used also for slope applications. It would obviously be desirable to have a still simpler (and cheaper) and reliable method developed allowing a larger number of measurements at low cost, but that is a separate matter, and the subject for a different symposium.

\subsection{Case study}

To illustrate one effect of different initial stresses on slope behaviour, a case study concerning a planned open pit mine and the possible influence of the pit excavation on a nearby major highway is presented. The objective of the work was to assess the influence from mining-induced ground deformations on the integrity of the highway, located $170-200 \mathrm{~m}$ from the planned pit crest. The pit is to be excavated in a Precambrian shield area, in which the initial horizontal stresses are thought to be larger than the initial vertical stress. Moreover, the site is close to a fairly large lake, which has formed along a large scale weakness zone, and a number of major regional structures exists, being oriented parallel and perpendicular to the long axis of the lake. No stress measurements have been conducted the site.

Based on literature review and experience, a strain criterion was defined to quantify mining influence. The criterion was formulated in terms of differential horizontal deformation or horizontal strain and the differential vertical deformation or vertical strain (tilt). An allowable strain limit of $0.3 \%$ horizontally and 
$0.2 \%$ vertically (tilt) was adopted, based on the susceptibility of critical infrastructure damage. It was judged that the tolerance for highways is higher; thus, these limits are conservative.

A two-dimensional numerical modelling approach was used, in which the pit excavation was simulated and the resulting strains at the location of the highway calculated. A two-dimensional model was judged sufficient for this task, considering the scarcity and uncertainty of input data and the assumption that any curvature of the pit walls would provide added confinement and less deformation. A sensitivity analysis was conducted in which rock mass properties, initial stresses, and phreatic level, were varied. The pit geometry and the chosen modelling section are shown in Figure 7.

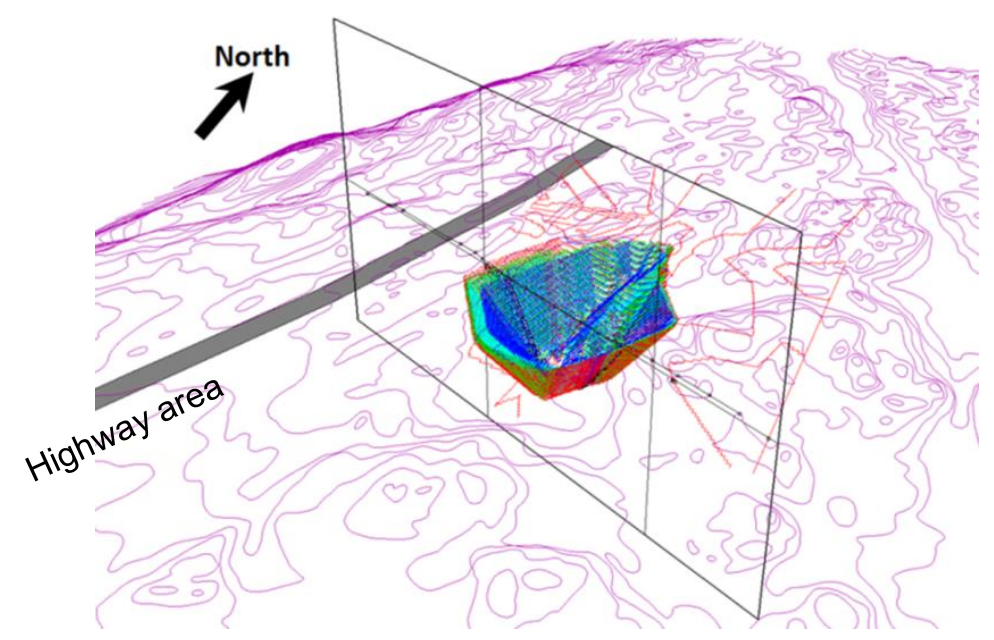

Figure 7 Perspective view showing preliminary open pit design, selected 2D modelling section, and highway area

A total of 30 cases, with varying rock quality, initial stress, and groundwater conditions, were analysed. Three different initial stress states were considered: (i) gravitational stresses only, (ii) $K=\sigma_{H} / \sigma_{v}=1.5$, and (iii) $K=3.0$. The results of the analyses were presented in terms of calculated strain and compared with the adopted strain limit presented above. An example of the obtained results for the assumed 'worst case' material properties is shown in Table 2. The results for vertical strain (tilt) are all below the assumed strain limit. For the horizontal strain, the limit is exceeded only for one case corresponding to 'worst case' rock mechanical properties, highly disturbed rock due to blasting, undrained conditions, and $K=3.0$. The influence of the initial stress state is clearly visible. In fact, it is only for the cases with $K=3.0$ that the strain values are even close to the assumed allowable limit.

The described case study is a good example of: (i) pragmatic use of numerical modelling, and (ii) possible stress effects on slope behaviour. In this particular case, the stresses did not appear to affect the overall stability of the slope, but they proved to be very influential on the ground deformations resulting from pit excavation. As discussed earlier, the assumed allowable strains are mainly applicable to critical infrastructure and higher tolerances apply for other, less sensitive, infrastructure, including roads.

Table 2 Calculated horizontal and vertical strain at the location of the highway due to mining of the open pit for the assumed 'worst' (lowest) rock mass strength and different initial stresses

\begin{tabular}{cccc}
\hline Stress State & Gravitational & $\boldsymbol{K}=\mathbf{1 . 5}$ & $\boldsymbol{K}=\mathbf{3 . 0}$ \\
\hline Horizontal strain & $0.02 \%$ & $0.08 \%$ & $0.34 \%$ \\
Vertical strain & $0.02 \%$ & $0.02 \%$ & $0.05 \%$ \\
\hline
\end{tabular}




\section{$4 \quad$ Beyond 2013 - a vision for the future}

\subsection{State-of-the-art}

The state-of-the-art in numerical modelling for rock slopes may be briefly summarised as follows:

- Three-dimensional modelling is now common in open pit applications.

- DFN models are used in many cases to replicate fracture configurations.

- Methods allowing explicit fracture propagation are emerging as practical tools.

- Coupled processes (water-stress) are modelled to a larger extent than before.

Given the current status, it is also clear that additional developments are required, e.g. within the subjects of model validation and input data collection. Some ideas for this are presented in the following.

\subsection{Validation needs}

The objective of a numerical model in rock mechanics is to provide a representation of the reality in computational form. The model should be able to replicate the rock mass behaviour (in sufficient detail) so that it can be used for prediction of future behaviour. To be able to assess whether a model is acceptable, it must be both verified and validated. Verification is defined as the process of determining that a computer model correctly represents the conceptual description and specification, e.g. ensuring that the computer model is an accurate implementation of an underlying mathematical model. In other words, verification is to certify that the computer model has been developed correctly ('that you built it right'). Validation is the process of determining the degree to which a model is an accurate representation of the real world from the perspective of the intended use(s). In other words, validation is to ensure that the model fulfils its use ('that you built the right thing'), see Missile Defense Agency (2008).

The process of model validation should not be confused with the concept of model calibration. Calibration involves adjusting input data (parameter values and/or material model) for a numerical model until the model output agrees with an observed behaviour. The fact that a model is calibrated for certain case does not mean that it will behave correctly for another case (with slightly different rock conditions). There is a need for stringent validation of numerical models. Critical comparisons of different approaches are seldom conducted or reported, which makes it difficult to judge the applicability of a particular approach.

It may be argued that full validation of numerical models through experiments will not be possible, since the complete geometry and properties of the rock mass will never be fully known (Jing, 2003). Thus, all validations can only be partial. The same point is made by Oreskes et al. (1994), claiming that any scientific hypothesis (of any kind) can never be validated, since there is always the possibility that more than one theory can explain observations or that future observations will invalidate a theory. However, this does not mean that we should give up trying to validate numerical models for mine design. Even if complete validation may not be possible, partial validation and the additional insight into understanding mechanisms provided will still be very useful. The question will then rather be what the acceptability criteria for a successful validation are? There is a need to define a set of acceptance criteria for validation of numerical modelling applied to slope stability problems.

\subsection{Input data improvements}

Advances in data collection and generation of input data have not kept equal pace to improvements in modelling techniques, and rock mechanics problems remain to a large extent data limited. Jing (2003) stated that a key issue for numerical modelling is "the development of advanced rock mass characterization techniques and modelling methods". Even the most extensive data sets available today only sample a small portion of the rock mass, so there is clearly a demand for more encompassing data collection and monitoring systems for future modelling improvements. This would also include performing stress measurements to a larger extent than previously for slope applications. 
An analogy may be made to the problem of mineral resource characterisation, in which different levels of confidence are used - inferred, indicated, measured - each one defined in terms of the amount and confidence of data required. The corresponding confidence levels for reserves are Possible, Probably and Proven. To convert mineral resources to ore reserves all the influencing factors should be known at the same level of confidence as the resources. The influencing factors can be geomechanical, mining, economical, societal, environmental, etc. (Steffen, 2007). The same confidence levels could thus be used for geomechanical data characterisation at a site, and thus for classifying input data to modelling, but this has yet to be applied in practice.

\subsection{Real-time modelling}

For the future, a move towards real-time modelling can also be envisioned. Real-time modelling is taken to mean numerical analysis in which the results are available in a time shorter than it takes for the modelled system to change. There have been great advances in this area, primarily driven by the increases in computing speed and capability over the last half century. Weather forecasting is a good example of where real-time modelling is important. If any calculations for weather predictions take longer than it takes for the weather to change, the results are of little practical use. The history of numerical weather prediction (often termed NWP) can be said to begin in the 1920s with the book 'Weather Prediction by Numerical Process' by Lewis Fry Richardson in 1922 (Richardson, 1965). The method proposed by Richardson remains, in principal, the basis for NWP of today (Stewart, 2003; Lynch, 2008).

With the arrival of computers, the ideas of Richardson could be employed more efficiently. In 1954, this model was used to produce the first operational (routine prediction for practical use) weather forecast by SMHI (the Swedish Meteorological and Hydrological Institute), and in 1955, operational weather forecasts begun in the United States (Stewart, 2003). The first seasonal climate model followed in 1956, for predicting monthly and seasonal patterns, and in the 1960s, atmospheric and oceanic processes were combined into the prediction models. In the early 1980s, the interaction of soil and vegetation with the atmosphere was included in the models. Presently, global weather models employ time steps of around 10 minutes, whereas regional models have time steps of one to four minutes.

The increase in calculation speed for the example above is about 10 orders of magnitude, over a time span of 50 years! The adherence to Moore's law (an empirical rule stating that the transistor count on an integrated circuit will double every two years) is remarkable, and the increases in performance also follow the same trend. Given these facts, it is not unrealistic to think that geomechanical numerical modelling may evolve in a similar way as weather forecasts. We are now at a point where realistic material models, replicating true rock mass behaviour, are close to being realised - although still at a small scale. If we add 50 years of increasing computer power, the concept of real-time modelling of geomechanical problems is not far-fetched any more. The tools are (almost) there and the challenge to develop real-time modelling approaches is now open for the creative mind!

\section{Acknowledgement}

Loren Lorig, CEO of Itasca International Inc., provided ideas and helped review this paper, which is greatly appreciated. The work on the case study described in Section 3.3 was conducted by Abel Sánchez Juncal and Diego Mas Ivars, both of Itasca Consultants AB.

\section{References}

Blake, W. (1968) Finite Element Model Study of Slope Modification at the Kimbley Pit, Transactions Society of Mining Engineers, Vol. 241, pp. 525-532.

Board, M., Chacón, E., Varona, P. and Lorig, L. (1996) Comparative Analysis of Toppling Behaviour at Chuquicamata Open-Pit Mine, Chile, Transactions of the Institution of Mining and Metallurgy (Sect. A:Mining industry), Vol. 105, pp. A11-A21.

Brawner, C.O. (1971) Chapter 1, Introduction, in Proceedings First International Conference on Stability in Open Pit Mining, C.O. Brawner and V. Milligan (eds), 23-25 November 1971, Vancouver, Society of Mining Engineering, New York, pp. 1-3. 
Broch, E. and Nilsen, B. (1982) Comparison of Calculated, Measured and Observed Stresses at the Ørtfjell Open Pit (Norway), Norwegian Hard Rock Tunneling, Publication No. 1, Norwegian Soil and Rock Engineering Association, Tapir Publishers, University of Trondheim, pp. 35-42.

Cala, M. and Flisiak, J. (2001) Slope Stability Analysis with FLAC and Limit Equilibrium Methods, FLAC and Numerical Modeling in Geomechanics - 2001, in Proceedings 2nd International FLAC Symposium on Numerical Modeling in Geomechanics, D. Billaux (ed), 29-31 October 2001, Lyon, France, Taylor \& Francis, pp. 113-114.

Cording, E.J. (1972) Stability of Rock Slopes: Proceedings Thirteenth Symposium on Rock Mechanics, E.J. Cording (ed), 30 August-1 September 1971, Urbana, Illinois, American Society of Civil Engineers, New York, 912 p.

Coulthard, M.A., Journet, N.C. and Swindells, C.F. (1992) Integration of Stress Analysis into Mine Excavation Design, Rock Mechanics, in Proceedings 33rd U.S. Symposium on Rock Mechanics, J.R. Tillerson and W.R. Wawersik (eds), 3-5 June 1992, Santa Fe, New Mexico, A.A. Balkema, Rotterdam, pp. 451-460.

Coulthard, M.A. and Little, T. (1999) Modeling of stability of high westwall at Ok Tedi Copper-Gold Mine, FLAC and Numerical Modeling in Geomechanics, in Proceedings International FLAC Symposium on Numerical Modeling, R. Hart and C. Detournary (eds), 1-3 September 1999, Minneapolis, USA, Taylor \& Francis, pp. 39-46.

Cundall, P.A. (2011) Lattice method for modeling brittle, jointed rock, Continuum and Distinct Element Numerical Modeling in Geomechanics - 2011, in Proceedings 2nd International FLAC/DEM Symposium, D. Sainsbury, R. Hart, C. Detournay and M. Nelson (eds), 14-16 February, 2011, Melbourne, Itasca International Inc., Minneapolis, pp. 67-74.

Cundall, P.A. and Strack, O.D.L. (1979) A discrete element numerical model for granular assemblies, Géotechnique, Vol. 29(1), pp. 47-65.

Dawson, E.M., Roth, W.H. and Drescher, A. (1999) Slope Stability Analysis by Strength Reduction, Géotechnique, Vol. 49(6), pp. 835-840.

Dight, P.M. (2006) Pit wall failures on 'unknown' structures, The Journal of The South African Institute of Mining and Metallurgy, Vol. 106, July 2006, pp. 451-458.

Dodd, J.S. and Anderson, H.W. (1972) Tectonic Stresses and Rock Slope Stability, in Proceedings Thirteenth Symposium on Rock Mechanics, Cording, E.J. (ed), 30 August-1 September 1971, Urbana, Illinois, American Society of Civil Engineers, New York, pp. 171-182.

Eberhardt, E. and Stead, D. (2011) Proceedings International Symposium on Rock Slope Stability in Open Pit Mining and Civil Engineering (Slope Stability 2011), 18-21 September, 2011, Vancouver, Canada, Canadian Rock Mechanics Association, Canada, CD-rom only.

Elmo, D., Clayton, C., Rogers, S., Beddoes, R. and Greer, S. (2011) Numerical Simulations of Potential Rock Bridge Failure within a Naturally Fractured Rock Mass, in Proceedings International Symposium on Rock Slope Stability in Open Pit Mining and Civil Engineering (Slope Stability 2011), 18-21 September, 2011, Vancouver, Canada, Canadian Rock Mechanics Association, Canada, CD-rom only.

Goodman, R.E. and Taylor, R.I. (1966) Methods of Analysis for Rock Slopes and Abutments, A Review of Recent Developments, in Proceedings 8th Symposium on Rock Mechanics, 15-17 September 1966, Minnesota, USA, American Rock Mechanics Association, Virginia, pp. 303-320.

Goodman, R.E., Taylor, R.L. and Brekke, T.L. (1968) A Model for the Mechanics of Jointed Rock, Journal of the Soil Mechanics and Foundation Division, American Society of Civil Engineers, May 1968, pp. 637-659.

Hoek, E. and Bray, J.W. (1981) Rock Slope Engineering, Institution of Mining and Metallurgy, London, 358 p.

Hoek, E., Hutchinson, J., Kalenchuk, K. and Diederichs, M. (2009) Appendix 3, Influence of in situ stresses on open pit design, Guidelines for Open Pit Slope Design, J. Read and P. Stacey (eds), CRC Press/Balkema, The Netherlands, pp. 437-445.

Hoek, E. and Pentz, D.L. (1968) The stability of open pit mines, Rock Mechanics Research Report No. 5, Departments of Civil Engineering, Geology and Mining and Mineral Technology, Imperial College of Science and Technology, London.

Hustrulid, W.A., McCarter, M.K. and Van Zyl, D.J.A. (2001) Slope Stability in Surface Mining, Society for Mining, Metallurgy, and Exploration, Inc. (SME), Littleton.

Itasca (2013) 3DEC, 3D Distinct Element Code, http://www.itascacg.com/software/3dec.

Jing, L. (2003) A review of techniques, advances and outstanding issues in numerical modelling for rock mechanics and rock engineering, International Journal of Rock Mechanics and Mining Sciences, Vol. 40, pp. 283-353.

Klerck, P.A., Sellers, E.J and Owen, D.R.J. (2004) Discrete fracture in quasi-brittle materials under compressive and tensile stress states, Computer Methods in Applied Mechanics and Engineering, Vol. 193, pp. 3035-3056.

Ko, K.C. (1972) Discrete Element Technique for Pit Slope Analysis, in Proceedings Thirteenth Symposium on Rock Mechanics, E.J. Cording (ed), 30 August - 1 September 1971, Urbana, Illinois, American Society of Civil Engineers, New York, pp. 183-199.

Lorig, L. (1999) Lessons learned from slope stability studies, FLAC and Numerical Modeling in Geomechanics, in Proceedings International FLAC Symposium on Numerical Modeling, R. Hart and C. Detournary (eds), 1-3 September 1999, Minneapolis, USA, Taylor \& Francis, pp. 17-21.

Lorig, L., Stacey, P. and Read, J. (2009) Chapter 10, Slope Design Methods, Guidelines for Open Pit Slope Design, J. Read and P. Stacey (eds), CRC Press/Balkema, The Netherlands, pp. 237-264.

Lynch, P. (2008) The origins of computer weather prediction and climate modeling, Journal of Computational Physics, Vol. 227, pp. 3431-3444.

Mas Ivars, D. (2010) Bonded Particle Model for Jointed Rock Mass, Doctoral Thesis, KTH-Engineering Geology and Geophysics Research Group, Department of Land and Water Resources Engineering, Royal Institute of Technology (KTH), ISBN 978-917415-559-4. 
Mas Ivars, D., Pierce, M.E., Darcel, C., Reyes-Montes, J., Potyondy, D.O., Young, R.P. and Cundall, P.A. (2011) The synthetic rock mass approach for jointed rock mass modelling, International Journal of Rock Mechanics and Mining Sciences, Vol. 48, pp. 219-244.

Mathtab, M.A. and Goodman, R.E. (1970) Three-Dimensional Finite Element Analysis of Jointed Rock Slopes, in Proceedings 2nd Congress International Society of Rock mechanics, September 1970, Belgrade, Vol. 3, pp. 7-12.

Missile Defense Agency (2008) Department of Defence Documentation of Verification, Validation \& Accreditation (VV\&A) for Models and Simulations, Washington, USA.

Munjiza, A. (2004) The combined finite-discrete element method, John Wiley \& Sons, Chichester, 348 p.

Napier, J.A.L. and Hildyard, M.W. (1992) Simulation of Fracture Growth Around Openings in Highly Stressed, Brittle Rock, Journal of the South African Institute of Mining and Metallurgy, Vol. 92(6), June 1992, pp. 159-168.

Nilsen, B. (1979) Stabilitet av höye fjellskjæringer, The University of Trondheim, The Norwegian Institute of Technology, Reports from the Department of Geology, August 11, 1979, 280 p.

Noorani, R., Ahangari, K. and Aloodari, S. (2011) The Influence of Horizontal Stress on the Failure Mechanism and Slope Stability in Chador-Malu Iron Open Pit Mine, in Proceedings International Symposium on Rock Slope Stability in Open Pit Mining and Civil Engineering (Slope Stability 2011), 18-21 September, 2011, Vancouver, Canada, Canadian Rock Mechanics Association, Canada, CD-rom only.

Nordlund, E. (2010) Teaching material, Luleå University of Technology, Luleå, Sweden.

Obara, Y., Nakamura, N., Kang, S.S. and Kaneko, K. (2000) Measurement of local stress and estimation of regional stress associated with stability assessment of an open-pit rock slope, International Journal of Rock Mechanics and Mining Sciences, Vol. 37(8), pp. 1211-1221.

Oreskes, N., Shrader-Frechette, K. and Belitz, K. (1994) Verification, Validation and Confirmation of Numerical Models in the Earth Sciences, Science, New Series, Vol. 263(5147), 4 February 1994, pp. 641-646.

Pariseau, W.G. and K. Stout (1972) Open Pit Mine Slope Stability: The Berkeley Pit, Stability of Rock Slopes, in Proceedings Thirteenth Symposium on Rock Mechanics, E.J. Cording (ed), 30 August-1 September 1971, Urbana, Illinois, American Society of Civil Engineers, New York, pp. 367-395.

Pentz, D.L. (1971) Chapter 8, Methods of Analysis of Stability of Rock Slopes, in Proceedings of the First International Conference on Stability in Open Pit Mining, C.O. Brawner and V. Milligan (eds), 23-25 November 1971, Vancouver, Society of Mining Engineering, New York, pp. 119-141.

Potvin, Y. (2007) International Symposium on Rock Slope Stability in Open Pit Mining and Civil Engineering (Slope07), Y. Potvin (ed), 12-14 September 2007, Perth, Australia, Australian Centre for Geomechanics, Perth, 543 p.

Potyondy, D.O. and Cundall, P.A. (2004). A bonded-particle model for rock, International Journal of Rock Mechanics and Mineral Science, Vol. 41, pp. 1329-1364.

Read, J. and Keeney, L. (2009) Chapter 3, Geological Model, Guidelines for Open Pit Slope Design, J. Read and P. Stacey (eds), CRC Press/Balkema, The Netherlands, pp. 53-67.

Read, J. and Stacey, P. (2009) Guidelines for Open Pit Slope Design, CRC Press/Balkema, The Netherlands.

Richardson, L.F. (1965) Weather Prediction by Numerical Process, Dover Publications, New York (originally published in 1922).

Shen, B. (1993) Mechanics of Fractures and Intervening Bridges in Hard Rocks, Doctoral Thesis, Royal Institute of Technology, Stockholm, Division of Engineering Geology.

Sjöberg, J. (1999) Analysis of the Aznalcollar Pit Slope Failures-A Case Study, FLAC and Numerical Modeling in Geomechanics, in Proceedings International FLAC Symposium on Numerical Modeling, R. Hart and C. Detournary (eds), 1-3 September 1999, Minneapolis, USA, Taylor \& Francis, pp. 63-70.

Stacey, T.R. (2007) Slope Stability in High Stress and Hard Rock Conditions, Slope Stability 2007, in Proceedings International Symposium on Rock Slope Stability in Open Pit Mining and Civil Engineering (Slope07), Y. Potvin (ed), 12-14 September 2007, Perth, Western Australia, Australian Centre for Geomechanics, Perth, pp. 187-200.

Stacey, T.R. (1973) Stability of Rock Slopes in Mining and Civil Engineering Situations, National Mechanical Engineering Research Institute, Council for Scientific and Industrial Research, CSIR Report ME 1202, Pretoria, 217 p.

Stacey, T.R. (1970) The Stresses Surrounding Open-Pit Mine Slopes, in Proceedings Symposium on the Theoretical Background to the Planning of Open Pit Mines with Special Reference to Slope Stability, P.W.J. Van Rensburg (ed), 29 August-4 September 1970, Johannesburg, South Africa, A.A. Balkema, Cape Town, pp. 199-207.

Stead, D., Coggan, J.S., Elmo, D. and Yan, M. (2007) Modelling brittle fracture in rock slopes: experience gained and lessons learned, Slope Stability 2007, in Proceedings International Symposium on Rock Slope Stability in Open Pit Mining and Civil Engineering (Slope07), Y. Potvin (ed), 12-14 Sept. 2007, Perth, Australian Centre for Geomechanics, Perth, pp. $239-252$.

Steffen, O. (2007) Mine planning - its relationship to risk management, Australian Centre for Geomechanics Newsletter, December 2007, viewed October 25, 2011, http://sponsored.uwa.edu.au/geomechanics/_data/page/2139/ACG.news.dec07.pdf.

Stewart, R. (2003) Weather Forecasting by Computer, viewed 18 October 2011, http://www.robinstewart.com/personal/learn/ $\mathrm{wfbc} /$.

Wines, D. and Hewson, S. (2011) Use of Three-Dimensional Distinct Element Numerical Modelling to Determine Ultimate Pit Slope Stability in Areas of Highly Dense Relict Underground Openings: Super Pit, Kalgoorlie, in Proceedings International Symposium on Rock Slope Stability in Open Pit Mining and Civil Engineering (Slope Stability 2011), 18-21 September 2011, Vancouver, Canada, Canadian Rock Mechanics Association, Canada, CD-rom only.

Zettler, A.H., Poisel, R., Roth, W. and Preh, A. (1999) Slope stability analysis based on the shear reduction technique in 3D, FLAC and Numerical Modeling in Geomechanics, in Proceedings International FLAC Symposium on Numerical Modeling in Geomechanics, R. Hart and C. Detournary (eds), 1-3 September 1999, Minneapolis, Taylor \& Francis, pp. 11-16. 